\title{
Keratinocyte Growth Factor Induces Proliferation of Hepatocytes and Epithelial Cells Throughout the Rat Gastrointestinal Tract
}

\author{
Regina M. Housley," Charles F. Morris, ${ }^{\ddagger}$ William Boyle, ${ }^{5}$ Brian Ring," Rebecca Biltz, „ John E. Tarpley," \\ Sharon L. Aukerman," Peter L. Devine,' Robert H. Whitehead, "* and Glenn F. Pierce" \\ Departments of $*$ Laboratory Animal Resources, ${ }^{\ddagger}$ Molecular Biology, ${ }^{8}$ Colon Cell Biology, and "Experimental Pathology, Amgen Inc., \\ Thousand Oaks, California 91320; 'Department of Obstetrics and Gynecology, Royal Brisbane Hospital, The University of Queensland, \\ Brisbane, Australia; and **The Ludwig Institute for Cancer Research, Royal Melbourne Hospital, Victoria, Australia
}

\begin{abstract}
Keratinocyte growth factor (KGF), a member of the fibroblast growth factor (FGF) family, was identified as a specific keratinocyte mitogen after isolation from a lung fibroblast line. Recently, recombinant (r)KGF was found to influence proliferation and differentiation patterns of multiple epithelial cell lineages within skin, lung, and the reproductive tract. In the present study, we designed experiments to identify additional target tissues, and focused on the rat gastrointestinal (GI) system, since a putative receptor, K-sam, was originally identified in a gastric carcinoma. Expression of KGF receptor and KGF mRNA was detected within the entire GI tract, suggesting the gut both synthesized and responded to KGF. Therefore, rKGF was administered to adult rats and was found to induce markedly increased proliferation of epithelial cells from the foregut to the colon, and of hepatocytes, one day after systemic treatment. Daily treatment resulted in the marked selective induction of mucin-producing cell lineages throughout the GI tract in a dose-dependent fashion. Other cell lineages were either unaffected (e.g., Paneth cells), or relatively decreased (e.g., parietal cells, enterocytes) in rKGF-treated rats. The direct effect of rKGF was confirmed by demonstrating markedly increased carcinoembryonic antigen production in a human colon carcinoma cell line, LIM1899. Serum levels of albumin were specifically and significantly elevated after daily treatment. These results demonstrate rKGF can induce epithelial cell activation throughout the GI tract and liver. Further, endogenous KGF may be a normal paracrine mediator of growth within the gut. (J. Clin. Invest. 1994. 94:1764-1777.) Key words: fibroblast growth factors - carcinoembryonic antigen $\cdot$ colon carcinoma $\cdot$ gastric $\cdot$ small intestine
\end{abstract}

\section{Introduction}

Keratinocyte growth factor (KGF/FGF-7) was initially purified and cloned from a lung fibroblast line as a soluble factor which

Address correspondence to Glenn F. Pierce, Ph.D., M.D., 15-2-A-226, Amgen Inc., Amgen Center, Thousand Oaks, CA 91320-1789.

Received for publication 10 January 1994 and in revised form 11 July 1994.

1. Abbreviations used in this paper: BrdU, bromodeoxyuridine; CEA, carcinoembryonic antigen; HGF, hepatocyte growth factor; PAS, periodic-acid-Schiff; rKGF, recombinant keratinocyte growth factor.

J. Clin. Invest.

(c) The American Society for Clinical Investigation, Inc.

$0021-9738 / 94 / 11 / 1764 / 14 \$ 2.00$

Volume 94, November 1994, 1764-1777 could stimulate keratinocyte proliferation by Rubin, Finch, and co-workers $(1,2)$. Although other members of the FGF and epidermal growth factor (EGF) families also stimulate keratinocytes, KGF was shown to be a more potent mitogen as well as a more potent differentiation agent in vitro (3). A direct role for KGF in keratinocyte proliferation was suggested by Werner and co-workers (4) in experiments using rodent dermal wounds, where KGF mRNA expression was observed to increase over 100 -fold $1 \mathrm{~d}$ after wounding. Studies by Miki et al. $(5,6)$ revealed that the basis for KGF selectivity was specific binding to a splice variant of FGF receptor 2 (FGFR2, bek), which is similar to K-sam, an activated receptor found in a gastric carcinoma cell line (7). Multiple other cell types examined, including endothelial cells, smooth muscle cells, and fibroblasts, which respond to other FGF family members, do not express the KGF receptor variant of FGFR2, and hence do not bind KGF (2).

Although KGF was thought to be an endogenous paracrine effector of keratinocyte growth in skin, it was originally isolated from a human lung fibroblast line and rat lung tissue was found to contain high levels of KGF and KGF receptor message (1, $2,8)$. Expression of the KGF transcript also has been detected in several stromal fibroblast cell lines derived from epithelial tissues of embryonic, neonatal, and adult human sources (2). KGF mRNA has not been detected in glial cells, brain nor in a variety of epithelial cell lines (2). In vivo, rKGF was found to induce proliferation of hair follicles, sebaceous glands, and regenerating keratinocytes within rabbit dermal wounds (9), and to influence basement membrane maturation in porcine wounds (10). Recently, rKGF was shown to induce proliferation of type II pneumocytes in vitro and in vivo $(8,11)$. In vivo, increased surfactant was found in the lungs of rats treated with rKGF (8). rKGF has also been shown to stimulate pancreatic ductal epithelia, mammary gland ductal epithelia, and to mediate androgen action in androgen-dependent epithelia such as the prostate and seminal vesicles (12-15).

Taken together, these observations imply that KGF is an endogenous paracrine effector for a variety of epithelial cells that is synthesized by underlying stromal fibroblasts. However, little information is available on the potential for KGF to influence epithelial tissues in the liver and gastrointestinal tract. The present results indicate that KGF is likely an important endogenous mediator of cell growth and differentiation in the gastrointestinal tract and liver, and that administration of pharmacologic amounts of rKGF has a highly significant inductive effect on specific epithelial lineages within these organs.

\section{Methods}

\section{Recombinant $K G F$}

A full-length cDNA clone of mature human keratinocyte growth factor was expressed in E. coli and purified to homogeneity using conventional 


\section{A}

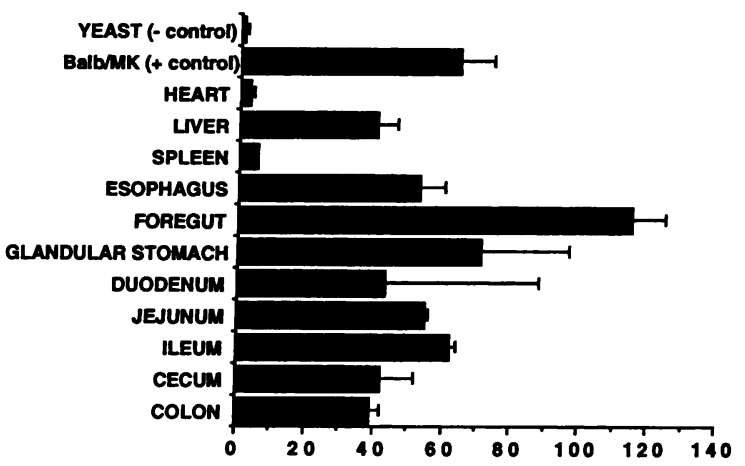

Equivalent Plcograms KGFR mRNA per 50 $\mu$ G total RNA

\section{B}

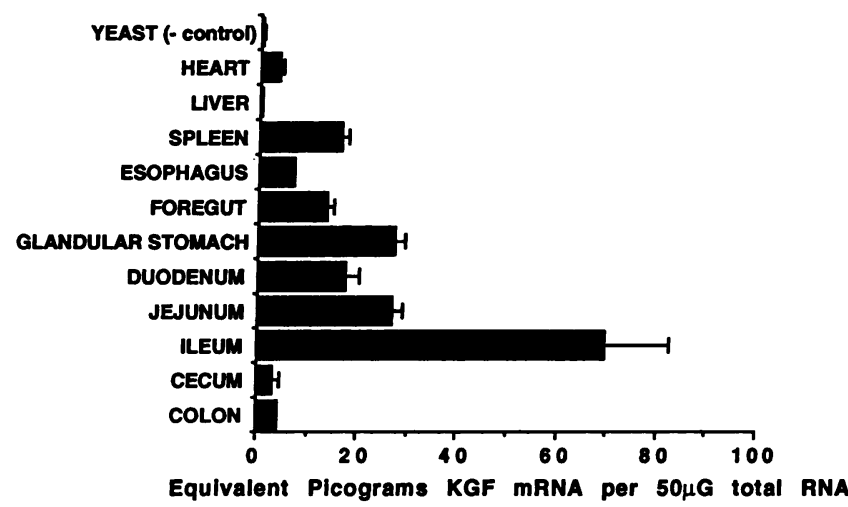

Figure 1. Expression of KGFR and KGF mRNAs in rat tissues. (A) KGF receptor mRNA expression. (B) KGF mRNA expression. RNA from adult rats was isolated and RNase protection assays performed on each tissue as described in Methods. The mean \pm standard deviation of triplicate samples are presented.

chromatography techniques. Each lot of rKGF was tested for endotoxin content, and specific activity on Balb/MK keratinocytes (American Type Culture Collection, Rockville, MD). In our serum-free assay system, half-maximal proliferation was observed at $\sim 19 \mathrm{ng} / \mathrm{ml}$. E. coli-expressed KGF has been reported to be up to 10 -fold more potent than natural material $(1,3,16)$.

\section{Animal injection paradigms}

Male, outbred, specific pathogen-free, Sprague Dawley rats (Charles River Laboratories, Wilmington, MA) were housed in microisolation and received potable water and food ad libitum. In a dose-response study, animals received rKGF or phosphate-buffered saline (PBS) by intraperitoneal injection daily for 4 days before sacrifice. In a second experiment, animals received $5 \mathrm{mg} / \mathrm{kg}$ rKGF or PBS for 1,4 , or $7 \mathrm{~d}$ before sacrifice. In a washout study, animals received rKGF or PBS for $4 \mathrm{~d}$ and cohorts of treatment and control animals were then sacrificed at zero, 7 and $21 \mathrm{~d}$ after treatment. In all experiments, at least five animals were analyzed per group and experiments were repeated.

\section{Blood and tissue collection and assay}

Rats were euthanatized by $\mathrm{CO}_{2}$ asphyxiation and serum was obtained by cardiac puncture immediately postmortem, then stored frozen until assayed for analytes (Medical Group Pathology Laboratory, Santa Barbara, CA, or Damon Laboratories, Thousand Oaks, CA). High resolution hepatic and serum protein electrophoreses, and alkaline phosphatase isoenzyme electrophoreses were performed following the manufactur-
Table I. Organ Weights of Rats Treated with rKGF for 1, 4, or $7 d$

\begin{tabular}{llcccc}
\hline & & & & Glandular & \\
Day & & Liver & Foregut & stomach & Colon \\
\hline & Control & $4.43 \pm 0.07 *$ & $0.18 \pm 0.13$ & $0.52 \pm 0.04$ & $0.92 \pm 0.03$ \\
1 & rKGF & $5.17 \pm 0.19$ & $0.21 \pm 0.12$ & $0.57 \pm 0.04$ & $1.00 \pm 0.05$ \\
& $P$ value & 0.006 & NS & NS & NS \\
& Control & $4.37 \pm 0.13$ & $0.14 \pm 0.01$ & $0.51 \pm 0.02$ & $0.91 \pm 0.04$ \\
4 & rKGF & $5.94 \pm 0.42$ & $0.33 \pm 0.05$ & $0.70 \pm 0.05$ & $1.19 \pm 0.04$ \\
& $P$ value & 0.007 & 0.007 & 0.0045 & 0.0009 \\
& Control & $3.49 \pm 0.06$ & $0.13 \pm 0.01$ & $0.48 \pm 0.02$ & $0.73 \pm 0.02$ \\
7 & rKGF & $4.08 \pm 0.08$ & $0.53 \pm 0.09$ & $0.65 \pm 0.01$ & $0.96 \pm 0.04$ \\
& $P$ value & 0.0003 & 0.0019 & 0.0001 & 0.0017 \\
& & & & & \\
\hline
\end{tabular}

* Mean \pm SE, $n=5$ per group, expressed as a percentage of body weight. ${ }^{\ddagger}$ Unpaired, two-tailed Student's $t$ test, rKGF $5 \mathrm{mg} / \mathrm{kg}$ vs. control; $N S$, not significant.

er's protocols (Ciba-Corning, Corning, NY). For alkaline phosphatase isoenzyme determination, positive controls included homogenates of liver, bone, and intestine. Carcasses were perfused through the left ventricle with $4 \%$ paraformaldehyde (Sigma Chemical Co., St. Louis, MO) using a peristaltic pump (Watson-Marlow Inc., Wilmington, MA). Major organs were weighed in a blinded fashion and weights were expressed as grams per $100 \mathrm{~g}$ body weight (percent body weight). The gut was divided into the esophagus, nonglandular foregut, glandular stomach, duodenum, jejunum, ileum, and proximal and distal colon. Tissue samples were fixed in $10 \%$ buffered formalin or $4 \%$ paraformaldehyde overnight for routine histological processing or in 2-methylbutane cooled by liquid nitrogen following embedding in OCT (Miles Inc., Elkhart, IN) for immunohistochemical, fat and carbohydrate staining. For RNase protection assays, tissues were immediately frozen on dry ice and stored at $-70^{\circ} \mathrm{C}$ until use.

\section{RNA isolation and RNase protection assay}

Total RNA was isolated from $1 \mathrm{~g}$ rat tissue as described by Chomczynski and Sacchi (17). For RNase protection mapping of KGFR and KGF transcripts, DNA probes were cloned into transcription vectors pGEM4Z and pSP72 (Promega, Madison, WI), respectively. The rat KGF antisense transcript used corresponds to nucleotides 132 to 336 (18). The KGFR antisense transcript used corresponds to nucleotides 1270 to 1417 (5). This region of KGFR sequence was determined to be identical in mouse and rat (Biltz, R., unpublished data). The vectors were linearized and radiolabeled antisense transcript was synthesized in vitro using SP6 or T7 RNA polymerase and [ $\left.{ }^{32} \mathrm{P}\right] \mathrm{rUTP}(800 \mathrm{Ci} / \mathrm{mmole}$; New England Nuclear, Boston, MA; $1 \mathrm{Ci}=37 \mathrm{GBq}$ ). The full length RNA probe was purified after electrophoretic separation on an $8 \%$ polyacrylamide/ $7 \mathrm{M}$ urea gel. For the RNase protection assay (Kit \#1410; Ambion, Inc., Austin, TX), triplicate samples of $50 \mu \mathrm{g}$ of total cellular RNA were hybridized at $45^{\circ} \mathrm{C}$ overnight with $10^{5} \mathrm{cpm}$ of appropriate antisense probe, then digested with RNase. The RNA:RNA hybrids were precipitated, resuspended, and separated on an $8 \%$ polyacrylamide/7 $\mathrm{M}$ urea gel. Signal from protected fragments was quantified on a Phosphorlmager (Molecular Dynamics Inc., Sunnyvale, CA) and averaged over the triplicate sample points. In order to quantify the amount of message in the various tissue samples, unlabeled sense RNA corresponding to the labeled antisense probe was synthesized, purified over a G50 spin column, quantified by $\mathrm{OD}_{260} \mathrm{~nm}$, and used as a standard for the hybridization assay. The equivalent picograms of message per $50 \mu \mathrm{g}$ of total RNA was calculated by comparison of each tissue RNA protected band signal to one derived from hybridization to the known standard of 'sense' RNA. The values obtained were then normalized using the ratio of the probe size to the full-length message. For the KGF RNase protection assay, triplicates were further normalized to the signal derived 
Table II. Serum Analytes of Rats Treated with rKGF for 1, 4, or $7 d$

\begin{tabular}{|c|c|c|c|c|c|c|c|}
\hline & & Albumin & Total protein & $\begin{array}{l}\text { Alkaline } \\
\text { phosphatase }\end{array}$ & Cholesterol & Triglycerides & BUN \\
\hline & & $(g / d l)$ & $(g / d l)$ & $(U / 2)$ & $(m g / d l)$ & $(m g / d l)$ & $(m g / d l)$ \\
\hline & Normal values* & $3.8-4.8$ & $5.6-7.6$ & $133-405$ & $40-130$ & $26-145$ & $13-18$ \\
\hline \multicolumn{8}{|l|}{ Day } \\
\hline \multirow[t]{3}{*}{1} & Control & $3.92 \pm 0.09^{\ddagger}$ & $6.00 \pm 0.19$ & $510 \pm 44$ & $76 \pm 2$ & $94 \pm 10$ & $15.8 \pm 0.4$ \\
\hline & rKGF & $3.78 \pm 0.11$ & $5.84 \pm 0.17$ & $482 \pm 29$ & $122 \pm 24$ & $261 \pm 72$ & $13.8 \pm 1.1$ \\
\hline & $P$ value $^{8}$ & NS & NS & NS & 0.097 & 0.05 & NS \\
\hline \multirow[t]{3}{*}{4} & Control & $3.76 \pm 0.08$ & $6.02 \pm 0.08$ & $511 \pm 48$ & $71 \pm 4$ & $125 \pm 17$ & $16.2 \pm 1.4$ \\
\hline & rKGF & $4.72 \pm 0.14$ & $7.48 \pm 0.28$ & $280 \pm 42$ & $242 \pm 33$ & $505 \pm 111$ & $11.8 \pm 0.2$ \\
\hline & $P$ value & 0.0003 & 0.0013 & 0.007 & 0.0008 & 0.0095 & NS \\
\hline \multirow[t]{3}{*}{7} & Control & $3.94 \pm 0.05$ & $6.20 \pm 0.10$ & $491 \pm 42$ & $75 \pm 7$ & $105 \pm 14$ & $17.2 \pm 0.3$ \\
\hline & rKGF & $5.0 \pm 0.09$ & $8.06 \pm 0.17$ & $225 \pm 21$ & $247 \pm 29$ & $506 \pm 63$ & $19.4 \pm 1.5$ \\
\hline & $P$ value & 0.0001 & 0.0001 & 0.0005 & 0.0004 & 0.0002 & NS \\
\hline
\end{tabular}

* Normal values for CD [CRL:CD(SD)BR] outbred rats, from references 55, 56. ${ }^{\ddagger}$ Mean $\pm \mathrm{SE}, n=5$ per group. ${ }^{8}$ Unpaired two-tailed Student’s $t$ test, rKGF $5 \mathrm{mg} / \mathrm{kg}$ vs. control; $N S$, not significant.

from a known amount of partial sense transcript (smaller than the protected fragment size) added into each reaction.

\section{Histochemical and immunohistochemical stains}

$1 \mathrm{~h}$ before sacrifice, rats received $50 \mathrm{mg} / \mathrm{kg}$ bromodeoxyuridine (BrdU; Aldrich Chemical Co., Milwaukee, WI) via intraperitoneal injection. To visualize $\mathrm{BrdU}$ incorporation into DNA of replicating cells, immunohistochemistry using a monoclonal anti-BrdU antibody (Dako, Carpenteria, CA) was performed using a biotinylated horse anti-mouse IgG secondary antibody and avidin-biotin complex (Vector Labs, Burlingame, CA), followed by 3,3-diaminobenzidine tetrahydrochloride (DAB; Sigma Chemical Co.) as described (9). Tissues were stained with hematoxylin and eosin, periodic-acid-schiff (PAS) (neutral mucins), Alcian blue at pH 2.5 (acid mucins), and Masson-Trichrome (19). Antibodies to villin (Chemicon, Inc., Temecula, CA), a brush border protein on enterocytes, were used to assess relative changes in enterocyte and goblet cell numbers on the mucosal surface of the small intestine. Antibodies to lysozyme (Dako) and serotonin (Chemicon, Inc.) were used to assess Paneth cell and enteroendocrine cell changes in the gut, respectively. Staining was performed using the TechMate 1000 using reagents and an avidinbiotin detection system supplied by its manufacturer (BioTek Solutions, Inc., Santa Barbara, CA). Frozen liver sections were stained with oil red $O$ and Sudan IV to detect lipids and with PAS to detect glycogen (19).

\section{Morphometric analyses}

Liver. The BrdU labeling index of the liver was determined by an individual blinded to the treatment groups using a light microscope with a calibrated eye objective grid. $10400 \times$ fields per liver were counted and averaged. Total nuclei, and labeled nuclei per unit area were counted. Each grid field consisted of $0.0625 \mathrm{~mm}^{2}\left(62,500 \mu \mathrm{m}^{2}\right)$ hepatic parenchyma. To standardize the fields counted as representing similar areas of hepatic parenchyma, all fields counted were adjacent to a portal triad. Mitotic figures per $400 \times$ field also were counted to confirm BrdU values.

GI tract. A calibrated eye objective micrometer was used to measure the thickness of the gastric mucosa and the depth of PAS positive cells within the gastric mucosa. Similarly, duodenal crypt depth, duodenal villus height, and colonic crypt depth in the proximal colon were measured. To quantify the changes in goblet cell production the number of PAS positive goblet cells was counted along $100 \mu \mathrm{m}$ lengths beginning at the base of the duodenal villi. In addition, the number of colonic crypts and the number of hyperplastic (bifurcated or trifurcated crypts) occupying a $100 \mu \mathrm{m}$ length of colonic mucosa were determined. In all areas of the gut, measurements were made only on glands or villi that appeared perpendicular to the underlying muscularis. 5-10 replicate measurements were made per animal and averaged.

Statistical analyses. All quantifiable data were analyzed using an unpaired two-tailed Student's $t$ test or one-way analysis of variance (ANOVA) for multiple group comparisons, followed by BonferoniDunn post-hoc analyses (Statview IV; Abacus Concepts, Berkeley, CA). Data are presented as mean \pm standard error of the mean (SE).

Immunohistochemistry of cultured LIM1899 cells. The LIM1899 colon carcinoma cell line was maintained as previously described (20). Cells were grown directly on Lab-Tek Chamber Slides (Lab-Tek Products, Inc., Naperville, IL) in RPMI 1640 containing 5\% fetal bovine serum in the presence or absence of $20 \mathrm{ng} / \mathrm{ml}$ rKGF for $5 \mathrm{~d}$. Cultures were washed with PBS, fixed with cold absolute acetone for $15 \mathrm{~min}$ and stained by indirect immunofluorescence using an IgM monoclonal antibody (mAb) 4E7, which recognizes an epitope on CEA, and fluorescein isothiocyanate-conjugated sheep anti-mouse IgG (Cappel, Inc., Arlington Heights, IL). mAb 4E7 was raised against the LS174T colon carcinoma cell line and shows similar staining on tissues and Western blots as CEA specific polyclonal antibodies (Devine, P.L., unpublished observation).

Immunochemical detection of CEA and related proteins. LIM1899 cells were cultured for $6 \mathrm{~d}$ in the presence or absence of $50 \mathrm{ng} / \mathrm{ml} \mathrm{rKGF}$. Media was collected for CEA immunoassays and Western blotting. Cells were harvested, solubilized in $1 \%$ sodium dodecyl sulfate (SDS), and extracts were Western blotted after separation on 3-15\% gradient SDSPAGE (21). mAb 4E7 was used to probe Western blots of cells and culture supernatant for the presence of CEA. A multi-determinant enzyme-linked immunoassay (ELISA) was performed on supernatants using 4E7-coated microtiter plates to capture antigen and rabbit polyclonal anti-human CEA (Dakopatts, Glostrup, Denmark) to detect bound antigen, followed by detection with anti-rabbit Ig-peroxidase (Silenus, Melbourne, Australia) as described (22). The IMx CEA microparticle enzyme immunoassay (Abbott Labs, Abbott Park, IL) was also used to quantify CEA levels in supernatants which had been concentrated fourfold in a 10,000 molecular weight cutoff centrifugal concentrator (Amicon, Beverley, MA).

\section{Results}

RNase protection assay. Both KGF receptor mRNA and KGF mRNA were detected in the gut of normal rats (Fig. 1). In most tissues examined, KGF receptor mRNA expression was 
CONTROL
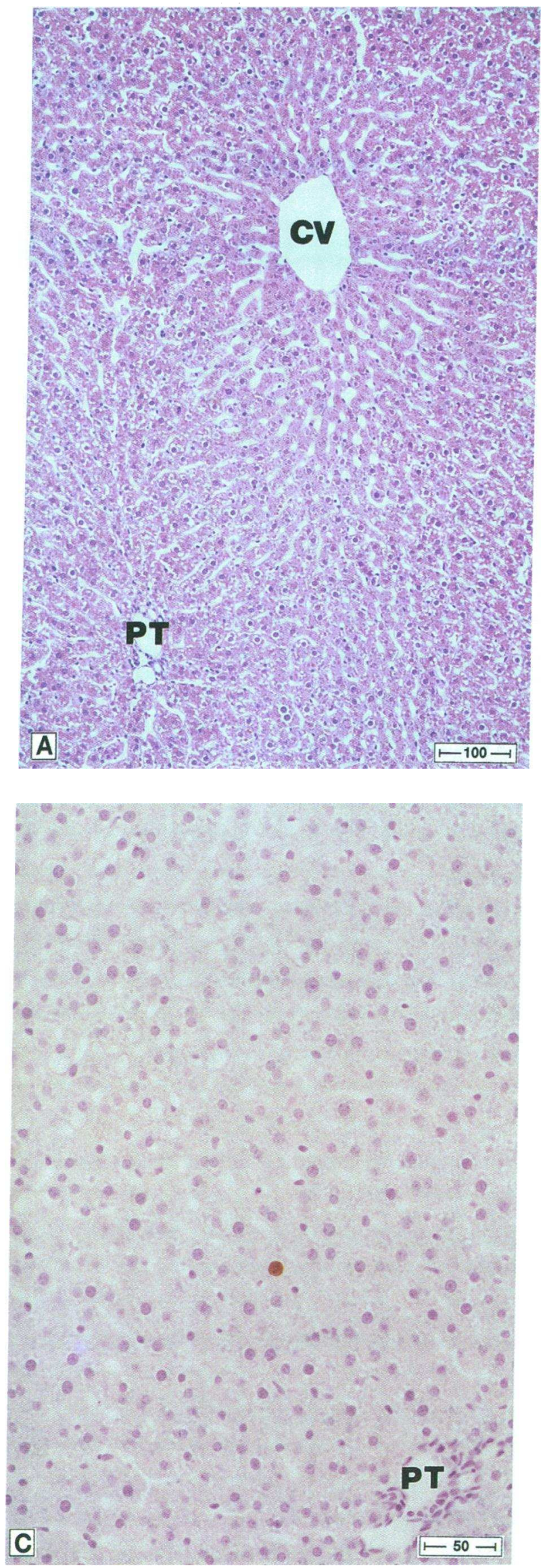

rKGF
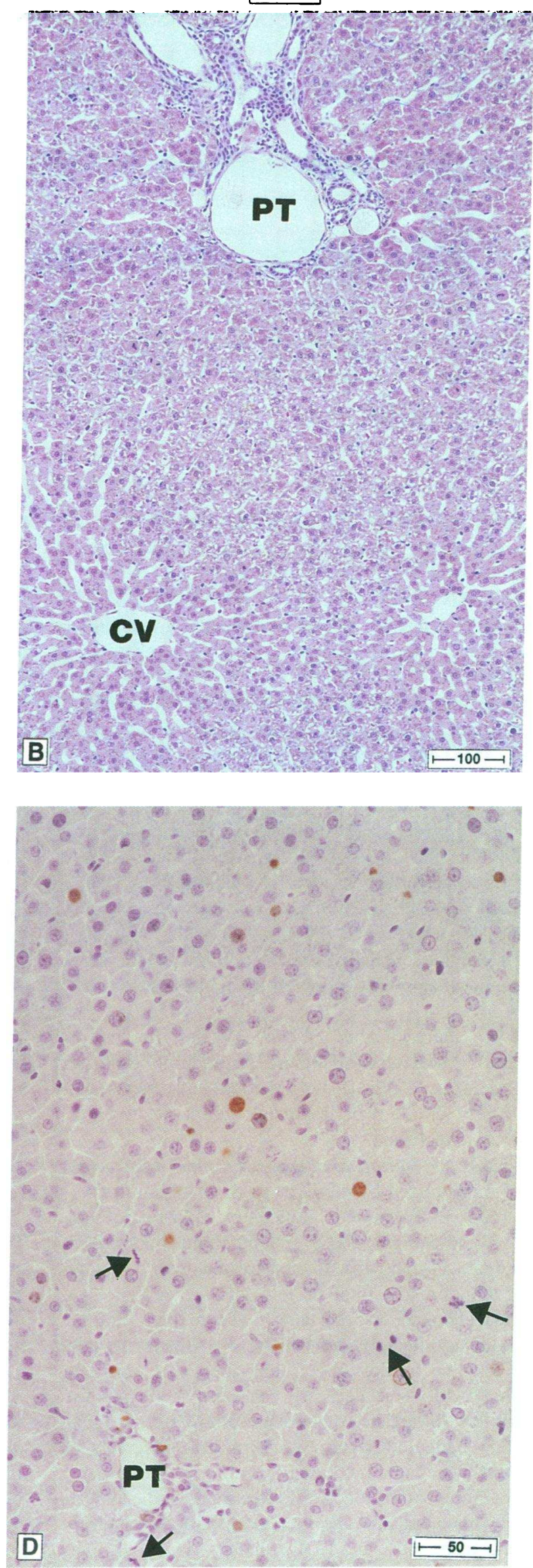

Figure 2. Histological analysis of rKGF-induced proliferation in the liver. Hepatic parenchyma in $(A)$ control and $(B)$, rKGF-treated rats $(H$ and E). Magnified view of $(C)$ control and $(D)$ rKGF-treated rats demonstrating BrdU positive hepatocytes after one day of treatment, counterstained with hematoxylin. Note increased mitotic figures in hepatocytes after KGF treatment (arrows). CV, central vein; $P T$, portal triad. 
A

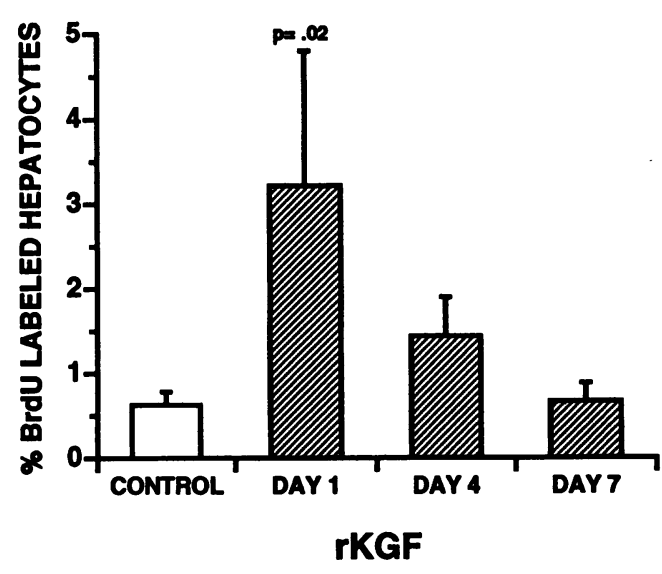

B

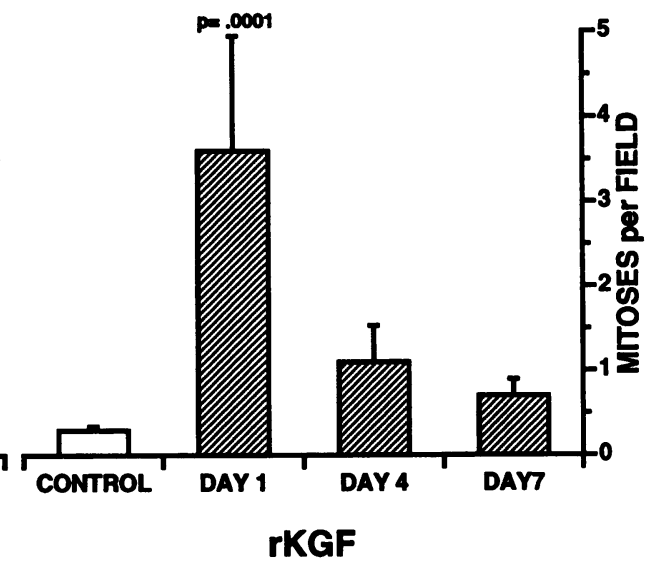

Figure 3. Increase in hepatocyte proliferation in response in rKGF. $(A)$ percent BrdU positive cells and $(B)$ mitotic figures per high power field within the hepatic parenchyma. severalfold higher than KGF mRNA expression. The liver showed the most disparity between receptor and ligand expression; although relatively high levels of receptor mRNA were present, no KGF mRNA was found. The spleen contained KGF, but little KGF receptor mRNA, raising the possibility that KGF may mediate effects in the liver in an endocrine manner, via the portal circulation. The nonglandular foregut showed the highest receptor expression of all tissues examined. Mesenchymal tissues such as the heart showed no ligand or receptor expression. The co-expression of both KGF and KGF receptor expression suggested that KGF might be important in stimulating growth in the gut mucosa.

Dose and day response studies with $r K G F$. To assess potential effects of rKGF in vivo on the liver and GI tract, a dose response study was performed to identify a pharmacologically active dose. rKGF from 0.2 to $5.0 \mathrm{mg} / \mathrm{kg}$ was injected daily for $4 \mathrm{~d}$, and tissues were harvested. Foregut, glandular stomach, colon, and liver weights, expressed as percent body weight were significantly higher than controls only at the highest dose (data not shown).

Animals were analyzed after 1,4 , or $7 \mathrm{~d}$ daily treatment with $5 \mathrm{mg} / \mathrm{kg}$ rKGF to determine the onset and duration of the organ weight changes (Table I). On necropsy, all organs appeared normal at 4 and $7 \mathrm{~d}$ of treatment except the foregut, which was grossly thickened.

Effect of $r K G F$ on serum analyses over time. Molecules synthesized or metabolized by the liver, such as albumin, cholesterol, and triglycerides were significantly elevated in sera obtained from 1 and $5 \mathrm{mg} / \mathrm{kg}$ rKGF-treated animals compared with controls (data not shown). In rats treated with $5 \mathrm{mg} / \mathrm{kg}$ $\mathrm{rKGF}$, serum albumin and total protein were increased at 4 d and remained elevated through day 7 (Table II). Alkaline phosphatase was significantly reduced by $4 \mathrm{~d}$ treatment with rKGF. When alkaline phosphatase isoenzymes were fractionated electrophoretically, the decrease could be accounted for almost entirely by diminished enterocyte-produced intestinal isoenzyme. No change in serum bilirubin was observed in rKGF-treated rats. The rapid increase of serum triglycerides and cholesterol beginning after $1 \mathrm{~d}$ rKGF treatment, indicated an influence on fat metabolism. The increased cholesterol levels were due to increased HDL and LDL fractions. The HDL/total cholesterol ratio was 0.6 in both rKGF-treated and control rats. The serum transaminases, aspartate aminotransferase (AST), and alanine aminotransferase (ALT) were minimally elevated (data not shown).

Blood urea nitrogen (BUN) and creatinine (data not shown) were similar in controls and rKGF-treated rats (Table II). These observations, coupled with no changes in body weights or hematocrits between groups suggested that hemoconcentration due to dehydration was not the cause of elevated serum proteins. The elevated serum proteins were subjected to high resolution electrophoresis. Sera from rKGF-treated animals showed only increased levels of albumin compared to controls. The albumin peak accounted for $60 \pm 4 \%$ of the total protein on rKGF-treated animals on day 7 , compared with $49 \pm 4 \%$ in controls. Other peaks showed no differences in protein content between groups (data not shown).

Hepatocyte proliferation. Liver weight was increased after as little as $1 \mathrm{~d}$ of rKGF treatment (Table II). A corresponding marked increase in hepatocyte proliferation was detected to 68-fold above controls, peaking after $1 \mathrm{~d}$ of rKGF treatment (Figs. 2 and 3). While hepatic hyperplasia was observed, hepatocyte hypertrophy was not detected in rKGF-treated rats, and hepatocyte density per unit area remained similar between the two groups (rKGF $879 \pm 11$ vs. $821 \pm 27$ ), suggesting increased numbers of hepatocytes were responsible for the increased liver weight. At day 7, mild biliary duct hyperplasia was present in treated animals. Taken together, the results in the liver suggest the burst of proliferation resulted in more protein-secreting differentiated hepatocytes.

Esophagus and stomach proliferation and differentiation. The foregut and glandular stomach, which contain KGF receptor mRNA, showed significant weight increases after 4 and $7 \mathrm{~d}$ treatment (Table I). Despite detecting KGF receptor mRNA, the esophagus was histologically normal and proliferation was not increased after rKGF treatment (Fig. 4, $A$ and $B$ ). The oral cavity was also unresponsive to rKGF. The mucosal surface epithelium of the esophagus changed abruptly at the cardia to the proliferative epithelium of the rKGF-treated foregut. At 4 d, the foregut epithelium was mildly thickened with a rete peglike appearance of skin, overlaying a normal appearing lamina propria. At $7 \mathrm{~d}$, the thickened keratinized epithelium covered polyp-like projections of lamina propria that extended up from the underlying muscularis into the lumen (Fig. 4, $C$ and $D$ ).

At 1,4 , and $7 \mathrm{~d}$ of rKGF treatment, the isthmus above the mucus neck cell layer, which contains progenitor cells, was 

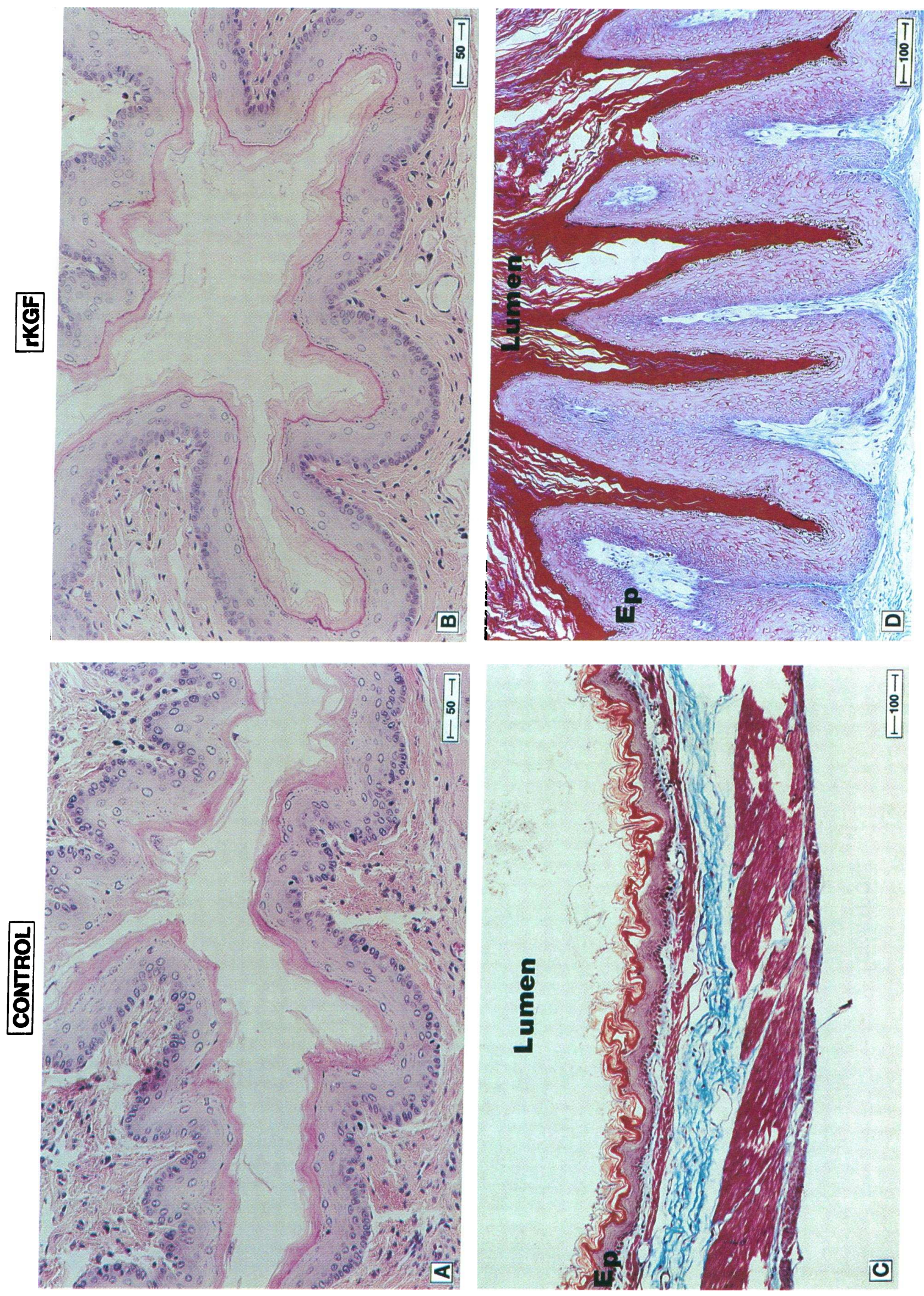

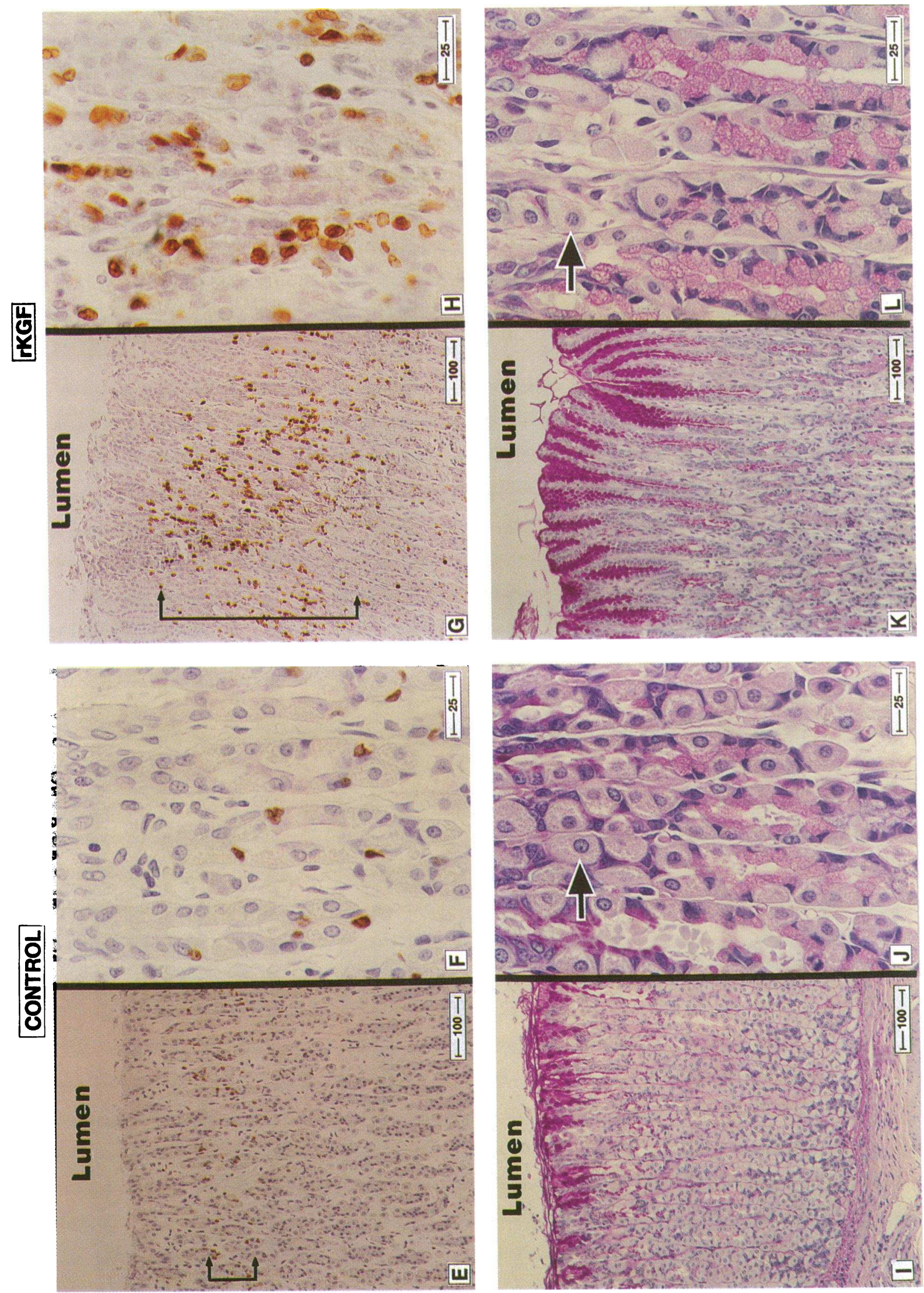


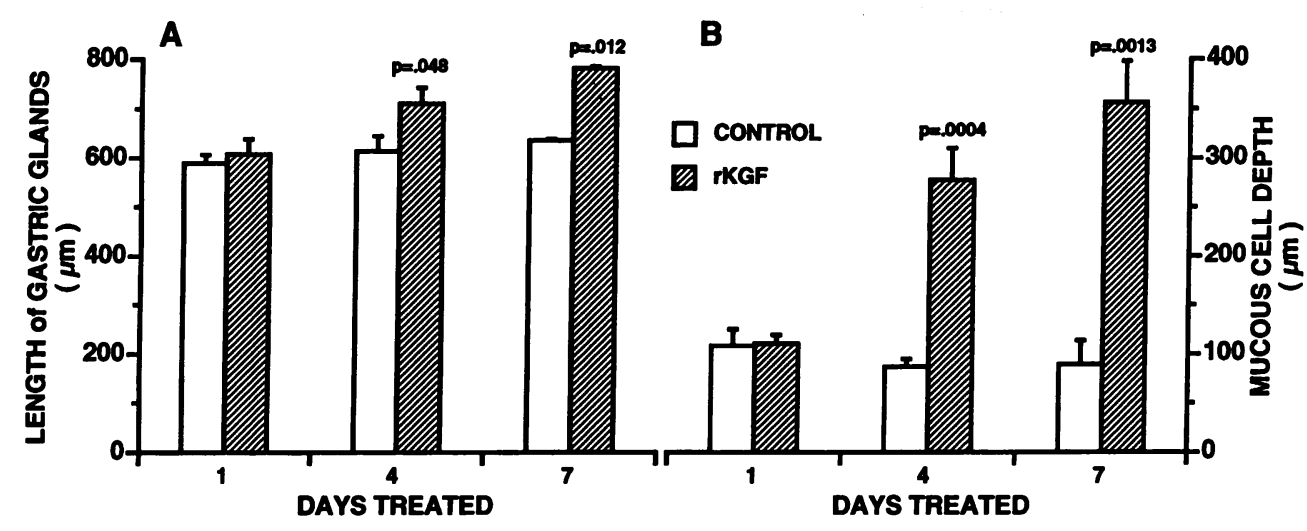

Figure 5. rKGF-induced changes in gastric mucosa. $(A)$ The length of the glandular gastric glands at 1,4 , and $7 \mathrm{~d}$ after intraperitoneal injection of $5 \mathrm{mg} / \mathrm{kg}$ body weight rKGF or PBS. (B) The depth of mucin extending from the lumen into the glandular gastric mucosa at 1,4 , and 7 days after intraperitoneal injection of $5 \mathrm{mg} / \mathrm{kg}$ body weight rKGF or PBS.

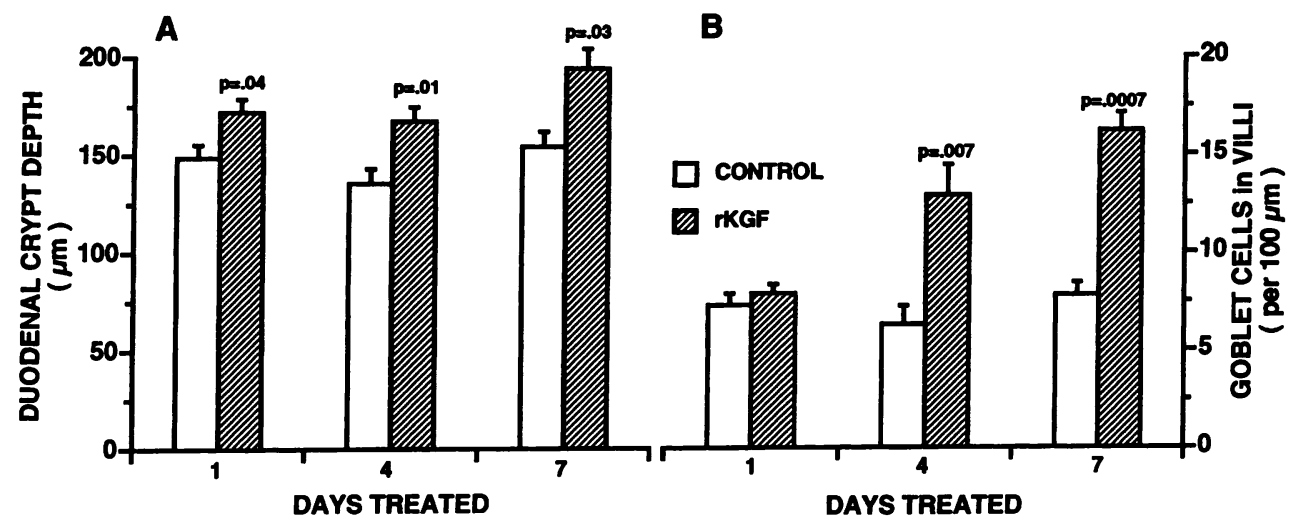

Figure 6. Increased duodenal crypt depth and numbers of goblet cells in rKGF-treated rats. $(A) \mathrm{Du}$ odenal crypt depth. (B) PAS positive goblet cells were counted at the base of duodenal villi. markedly widened with numerous BrdU positive proliferating cells and displaced toward the serosal surface (Fig. 4, E-H). By 4 and $7 \mathrm{~d}$ of rKGF treatment, increased numbers of gastric pit mucin-producing cells were detected throughout the glandular gastric mucosa (Figs. 4, I-L). A corresponding decrease in the number of parietal cells also was observed in rKGF-treated rats. Animals treated with rKGF for 4 and $7 \mathrm{~d}$ had mildly elongated gastric glands (Fig. $5 \mathrm{~A}$ ). The depth of the mucous layer from the luminal surface of the gastric mucosa was also markedly increased after $4(P=0.0004)$ and $7(P=0.001)$ days rKGF treatment (Fig. 5 B). Mucin appeared qualitatively normal. More mature mucin-producing gastric pit cells approaching the lumen no longer proliferated (Fig. 4, $E-H$ ).

Small intestinal tract proliferation and differentiation. The small intestine appeared grossly normal at all study points. The depth of duodenal crypts was significantly increased beginning after $1 \mathrm{~d}$ of treatment (Fig. $6 \mathrm{~A}$ ). Markedly increased numbers of mucus producing goblet cells within crypts and villi were detected after 4 and $7 \mathrm{~d}$ of rKGF treatment (Figs. $6 B$ and 7). Villus heights were not increased in rKGF-treated rats, suggesting that the increased numbers of cells contained within crypts may have accelerated transit times through villi.

Colon proliferation and differentiation. The net weight of the colon was increased at days 4 and 7 in rKGF-treated rats (Table I). By $7 \mathrm{~d}$, the proximal colonic mucosa developed rugallike folds that greatly increased the overall surface area. Bifurcated and trifurcated colonic crypts, which indicate crypt fission, were most prominent after $1 \mathrm{~d}$ rKGF treatment (Figs. $8 \mathrm{~A}$ and $9, A$ and $B$ ). There was no difference in the total number of crypts per unit area at any treatment time point (data not shown). The depth of colonic crypts increased after $7 \mathrm{~d}$ (Fig. $8 \mathrm{~B}$ ). The distal colon also demonstrated similar hyperplastic changes.

A dramatic increase in mucus producing goblet cells throughout the proximal and distal colon was detected in rKGFtreated rats using Alcian blue stain (Fig. 9, $C$ and $D$ ). In controls the number of goblet cells decreased toward the luminal surface

Figure 4. Histological analysis of the esophagus, foregut and glandular stomach of control and $5 \mathrm{mg} / \mathrm{kg} \mathrm{rKGF}$-treated animals. $\mathrm{H}$ and $\mathrm{E}$ of the esophagus of $(A)$ control or $(B)$ rKGF-treated after $7 \mathrm{~d}$ showing no effect. Trichrome staining of $(C)$ control foregut and (D) rKGF-treated foregut after $4 \mathrm{~d}$ showing proliferation and hyperkeratinization of squamous epithelium (Ep). Glandular stomach containing BrdU positive cells primarily in the isthmus above the mucus neck cell zone in $(E)$ control and expanded in $(G)$ rKGF-treated rats after $7 \mathrm{~d}(b r a c k e t s)$. At higher magnification, proliferation in the mucus neck cell zone is considerably less in $(F)$ controls compared with $(H)$ rKGF-treated rats. PAS staining of the glandular stomach in $(I)$ control and $(K)$ rKGF-treated rats demonstrating increased mucin production and decreased numbers of parietal cells in gastric glands in rKGF-treated rats. At higher magnification of the mucus neck cell zone $(J)$, controls contain considerably more parietal cells $($ arrows) than $(L)$ rKGF-treated animals. 
CONTROL
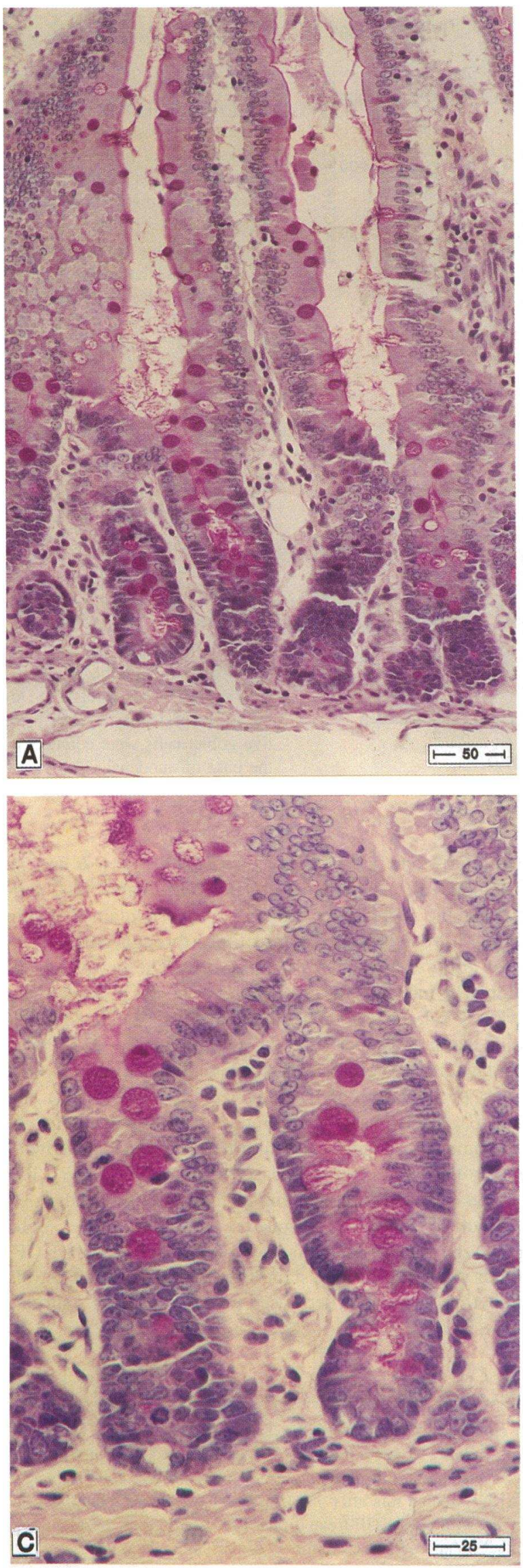

rKGF
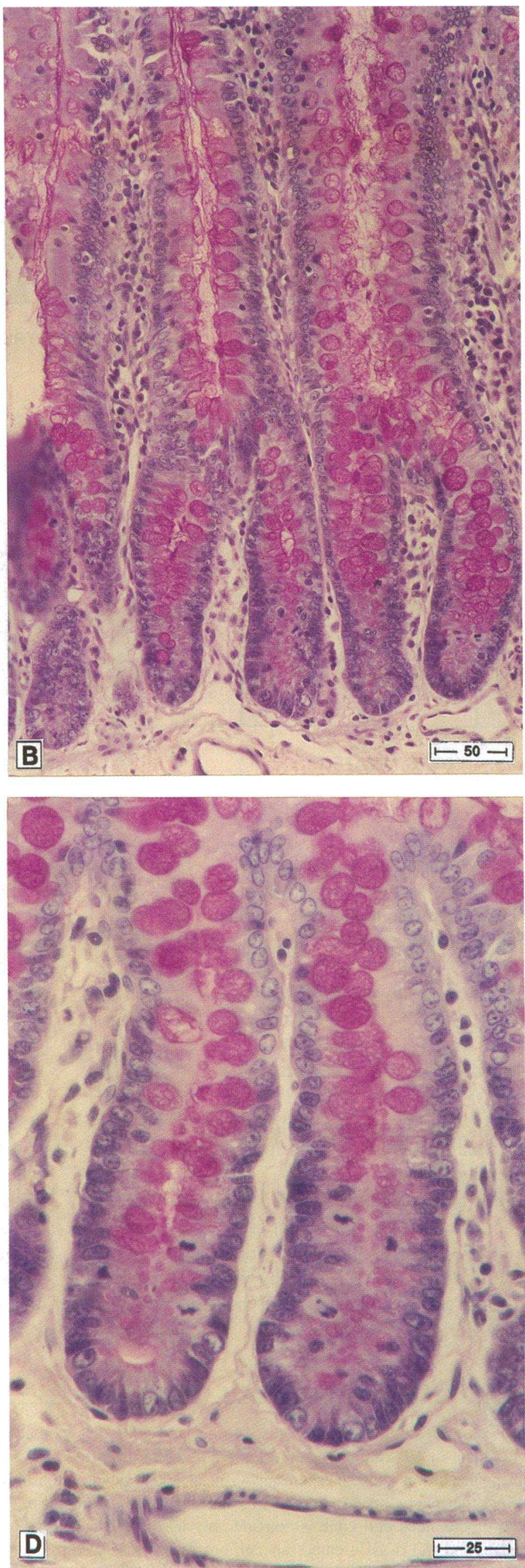

Figure 7. Increased mucin-producing cells within duodenal villi and crypts in 4-d $5 \mathrm{mg} / \mathrm{kg}$ rKGF-treated rats. $(A)$ control; $(B)$ Increased number of PAS positive goblet cells within villi and crypts in rKGF-treated animal. Higher magnification views of crypts from $(C)$ control animals and $(D)$ rKGF treated animals containing increased mitotic figures and increased goblet cells. 
A

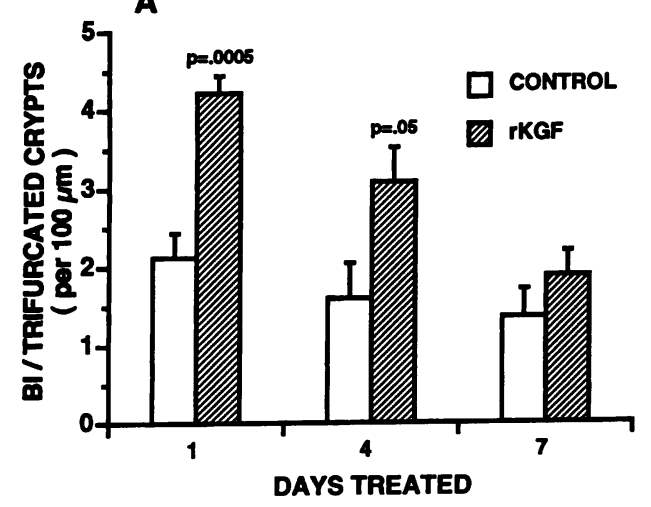

B

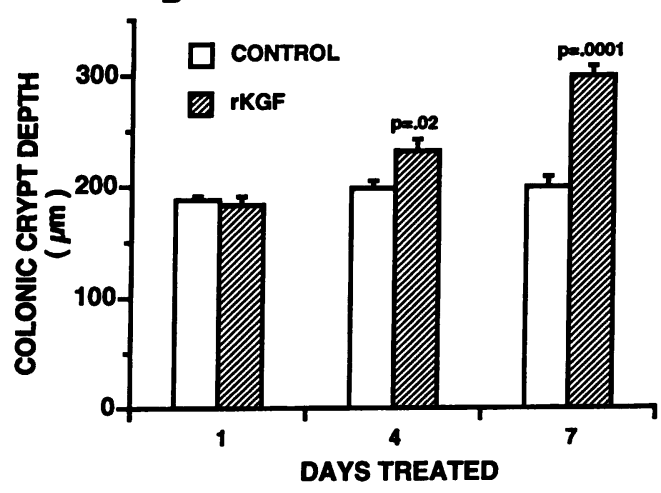

Figure 8. Increased hyperplastic colonic crypts and crypt depth in rKGF-treated rats. $(A)$ The average number of bifurcated and trifurcated colonic crypts present along a $100-\mu \mathrm{m}$ linear section of proximal colon at 1,4 , and $7 \mathrm{~d}$ after intraperitoneal injection of $5 \mathrm{mg} / \mathrm{kg}$ body weight rKGF or PBS. (B) Colonic crypt depth showing the average depth of colonic crypts at 1,4 , and 7 $d$ after intraperitoneal injection of $5 \mathrm{mg} / \mathrm{kg}$ body weight rKGF or PBS. of colonic crypts leaving only an occasional positive cell in the luminal one third of the crypt. In contrast, treatment animals as early as $4 \mathrm{~d}$ showed marked increases in goblet cells in the upper one-half of the colonic crypts. By $7 \mathrm{~d}$ treatment the crypt lumen was obscured and appeared packed with goblet cells which extended throughout the entire length of the crypt. Alcian blue and PAS staining yielded similar results, indicating that mucins induced by rKGF were qualitatively normal though markedly increased.

Analysis of specific cell lineages. The goblet cell lineage was clearly increased throughout the gastrointestinal tract. Villin, a marker of the brush border on enterocytes, was diminished at the lumenal surface after $7 \mathrm{~d}$ rKGF treatment, compared with control colonic sections (data not shown), consistent with the observed decrease in intestinal-derived serum alkaline phosphatase (Table II). Paneth cells, located at the base of crypts in the small intestine, did not appear to change in number with rKGF treatment, using lysozyme as a marker. Enteroendocrine cells, the fourth major cell type in the gut, were rare in both rKGFtreated and control animals, using serotonin as a marker. Taken together, these observations suggest the finding of more goblet cell-specific lineage stimulation by rKGF.

Immunodetection of carcinoembryonic antigen in the colon carcinoma cell line LIM1899. Immunofluorescent analysis of LIM1899 cells using 4E7 antibody, which identifies CEA, demonstrated markedly increased numbers of positive cells and intensity of fluorescence in rKGF-treated, compared with control cell cultures (Fig. 10, $A$ and $B$ ). Western blotting of LIM1899 cell extracts and conditioned medium using 4E7 and anti-CEA (data not shown) confirmed the specific induction of CEA synthesis in rKGF-treated cells (Fig. 11). Furthermore, the reactivity of a large panel of anti-mucin monoclonal antibodies (22) was unaffected by rKGF treatment, confirming the specific induction of CEA (data not shown). A multi-site ELISA, in which 4E7 was used to capture CEA and polyclonal anti-CEA was used for detection, demonstrated a fourfold increase in secreted CEA from rKGF-treated cells (dilution for $\mathrm{OD}_{405} \mathrm{~nm}=0.5$ was $1 / 8$ for the untreated culture and $1 / 32$ for the KGF-treated culture). These results were further demonstrated using the Abbott CEA immunoassay, where rKGF-treated culture supernatant contained $233 \mathrm{ng} / \mathrm{ml}$ CEA, compared with $94 \mathrm{ng} / \mathrm{ml}$ CEA in untreated culture supernatant. Although the degree of stimulation varied with the assay and antibodies used for detection of CEA, rKGF specifically induced markedly increased CEA in all assays.

Transience of $r K G F$-induced changes. A washout study was conducted in animals treated daily for $4 \mathrm{~d}$ with $5 \mathrm{mg} / \mathrm{kg}$ rKGF to determine the duration of effects on the liver and GI tract. Most organ weights from rKGF-treated animals were significantly different from controls only at day zero post-treatment (4th treatment day). By day 7 post-rKGF treatment all organ weights returned to normal except for the liver, which normalized by $21 \mathrm{~d}$ after cessation of treatment (data not shown). Liver, glandular stomach, small intestine and colon were histologically similar to controls at both 7 and $21 \mathrm{~d}$ after treatment. Serum proteins remained slightly elevated through day 21 post-rKGF, likely reflecting their long circulating half-lives (data not shown). Cholesterol and triglyceride levels returned to normal by $7 \mathrm{~d}$ after treatment.

\section{Discussion}

$K G F$ and hepatocytes. The present results demonstrate potent mitogenic and differentiative effects on specific epithelial tissues of the gastrointestinal system after in vivo administration of pharmacologic doses of rKGF. The rapid increase in liver weight after $1 \mathrm{~d}$ of rKGF treatment is likely due to the transient burst of hepatocyte proliferation in this largely quiescent epithelial tissue. Since hepatocyte cell size did not change in treated animals, the increased liver weight was due primarily to a transient increase in the number of hepatocytes, and resultant hepatic hyperplasia. Hepatic KGFR mRNA was not downregulated after 4 and $7 \mathrm{~d}$ of KGF treatment (Biltz, R., unpublished observation), thus the reason(s) why hepatocytes stop responding to proliferative signals from rKGF after the initial round of proliferation is not clear. The specific cells within the liver that are the targets of rKGF are not presently defined. However, since rKGF did not induce all hepatocytes to enter the cell cycle, the target may be a subpopulation which retains relatively more proliferative capacity, such as oval cells derived from a hepatic stem cell compartment (24). Finding bile duct hyperplasia and pancreatic ductal hyperplasia (12) also in rKGF-treated rats is consistent with their shared lineage with hepatocyte precursors.

Other epithelial cell mitogens, including epidermal growth factor (EGF)/transforming growth factor $\alpha$ (TGF- $\alpha$ ), acidic fibroblast growth factor (aFGF), and hepatocyte growth factor (HGF) stimulate hepatocyte proliferation in vitro, and after partial hepatectomy or other forms of liver injury $(25-30)$. Recently, rKGF has been found to be mitogenic for cultured rat hepatocytes $(31,32)$. Interestingly, recent work by Webber and colleagues (30) has found that HGF, EGF, or TGF $\alpha$ adminis- 
CONTROL
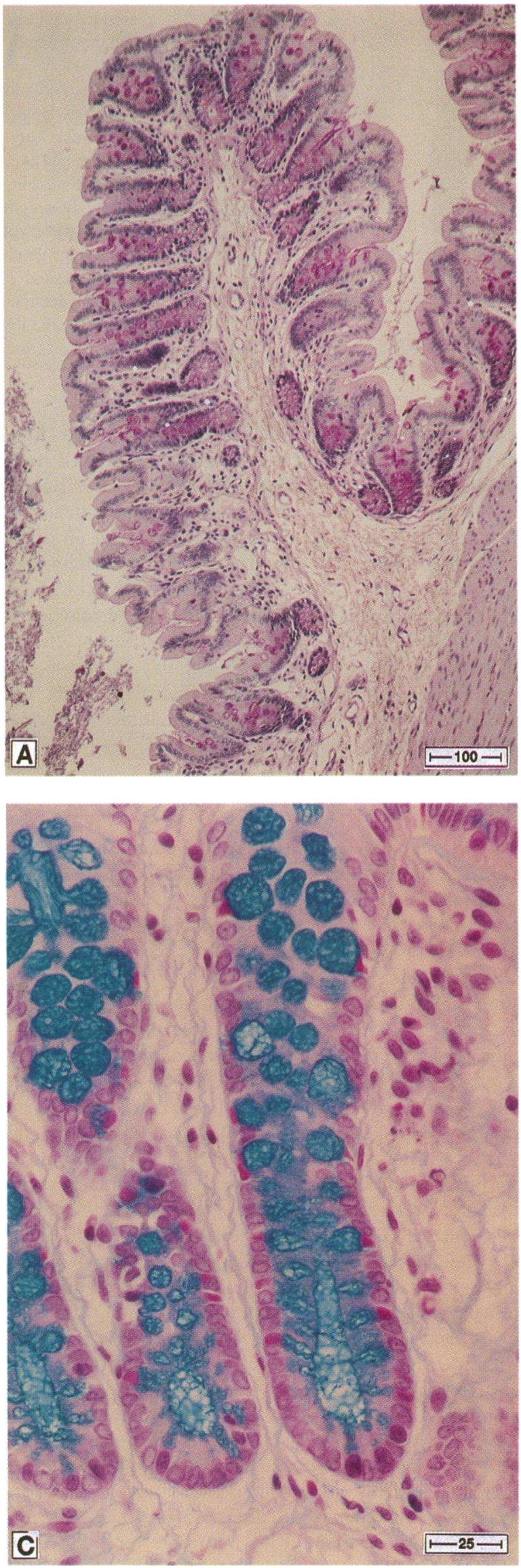

rKGF
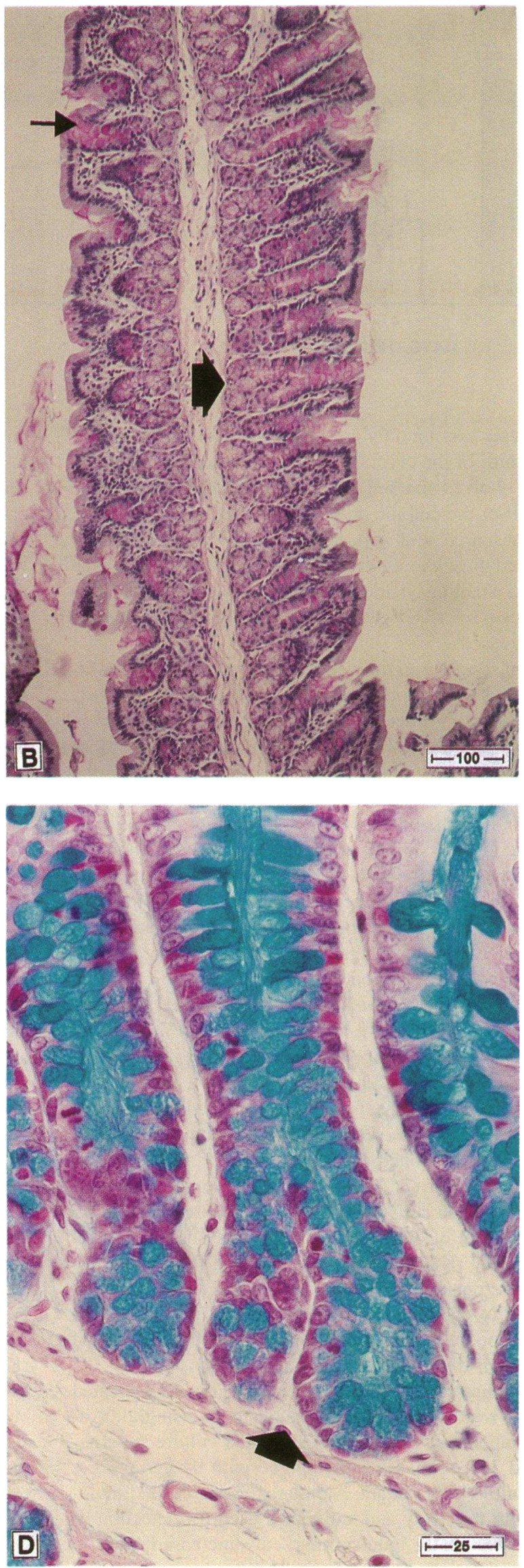

Figure 9. Histological analysis of proximal colon crypts in rKGF-treated rats. PAS staining of proximal colon in $(A)$ control and $(B)$ rKGF-treated rat. Note increased number of bifurcated and trifurcated crypts after $1 \mathrm{~d}$ of rKGF treatment. Large arrows show examples of hyperplastic crypts. Small arrow shows the increased density of mucin the upper one-third of crypts. Alcian blue staining in a $(C)$ control and $(D)$ rKGF-treated rat after $4 \mathrm{~d}$ showing increased density of mucin-producing cells throughout the crypts in rKGF-treated animals. 

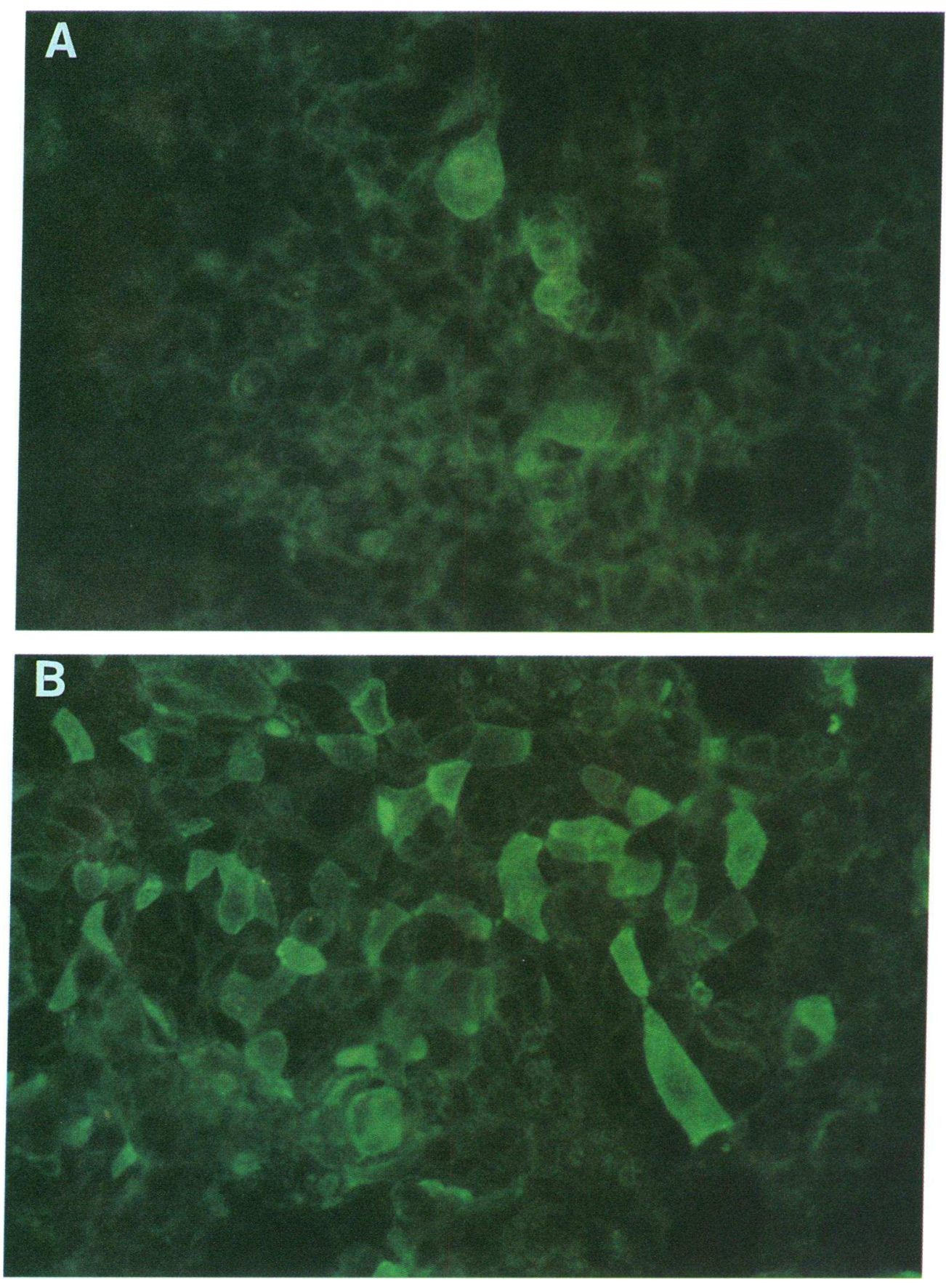

Figure 10. rKGF-induced modulation of CEA in colon carcinoma cell line LIM1899. $A$, control cells; $B$, rKGF treated cells. LIM1899 cells were cultured in RPMI 1640 containing 5\% FBS in the presence or absence of rKGF as described in Methods. The number of cells specifically stained with monoclonal antibody 4E7 was markedly increased in cultures grown in the presence of rKGF.

tered to animals had minimal effects on DNA synthesis in intact livers, in contrast to the marked effects observed with rKGF in the present study.

$K G F$ and the gastric mucosa. The mechanisms behind the massive proliferation of the foregut with apparent sparing of the esophagus are unknown, since KGF receptor message was detected in both tissues. These two tissues are histologically similar in appearance and respond similarly to EGF administered to mice (33). The present results suggest the nonglandular foregut, which is not present in humans, is distinct from the esophagus.

rKGF induced the marked expansion of progenitor cells in the isthmus above the mucus neck layer of the glandular stomach. Similarly, EGF, TGF $\alpha$, and HGF stimulate proliferation in the gastric mucosa in vitro (34-36). After division cells from this layer migrate upwards, toward the gut lumen to form mucin surface cells or downward, toward the serosal surface, to generate other differentiated cell types that occupy the gastric glands. While rKGF promotes selective proliferation of mucus neck cells which move toward the lumen, it appears to induce a depletion of parietal cells, suggesting both cell types arise from the same multipotential lineage which responds to rKGF selectively. It is not yet clear whether chief cells and $G$ cells, which are also thought to arise from the same multipotential progenitor, are affected by rKGF.

$K G F$ and the small intestine and colon. The rapidity with which rKGF increases intestinal crypt cells (by $24 \mathrm{~h}$ ) as measured by crypt depth is not surprising since the cell cycle time 


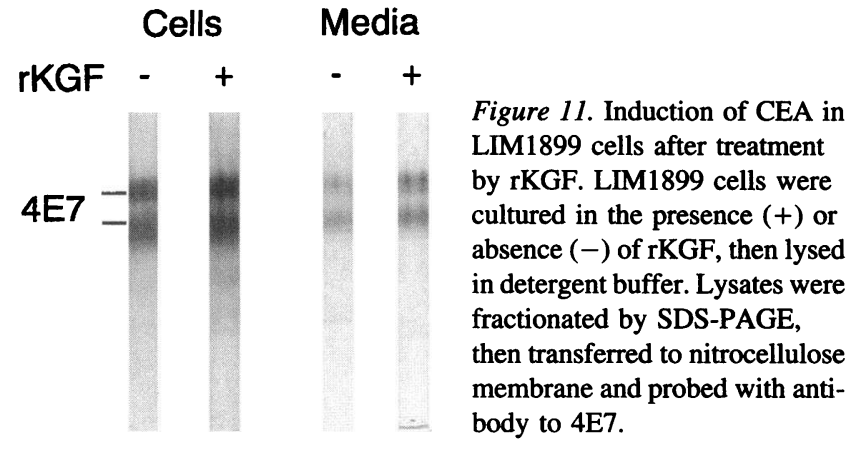

in the proliferating zone of the small intestinal crypt is 9 to 13 $h(37,38)$. Small intestinal crypts contain fixed pluripotent stem cells that give rise to precursor cells of the four intestinal cell types, goblet cells, enterocytes, enteroendocrine cells, and $\mathrm{Pa}-$ neth cells (38-40). rKGF induced elongation of crypts and specifically increased goblet cell differentiation on the villi. The rKGF targets in the crypts have not yet been identified, and may be either multipotential progenitors (stem cells) or specific goblet cell precursors (41).

Enterocytes normally comprise the bulk of the epithelial cells covering the small intestinal villi (42), yet were eclipsed by goblet cells in rKGF-treated villi, findings which are directly supported by finding diminished serum alkaline phosphatase of intestinal origin. rKGF does not appear to influence Paneth and enteroendocrine cells. Experiments using chimeric transgenic mice over-expressing specific markers for the differentiated cell types within the small intestine (41-43) should be useful in more precisely identifying rKGF targets.

In the large intestine early crypt hyperplasia was followed by crypt elongation in rKGF-treated animals. The mechanisms of new crypt generation are not understood but are thought to involve budding from pre-existing crypts (fission). rKGF may be targeting a stem cell population capable of not only elongating crypts and increasing goblet cell differentiation, but of generating new crypts as well (44). The relative diminution in enterocytes detected in the small intestine also was observed in the colon of rKGF-treated animals.

CEA is a member of the immunoglobulin superfamily which mediates cell adhesion, and has been identified in normal colonic epithelial cells and in most colon carcinomas (20, 45, 46). Differentiation inducers such as sodium butyrate have been shown to increase CEA production in colon carcinoma and adenoma cell lines, largely via increased transcription of CEA mRNA (47). We observed specific induction of CEA in the colon carcinoma cell line LIM1899, after treatment with rKGF. Since mucus producing goblet cells clearly are increased following rKGF treatment, these in vitro findings support the notion that goblet cell precursors are a KGF target.

Other growth factors also are capable of influencing cells in the GI tract. TGF $\alpha$ has been detected throughout the mucosa of the gastrointestinal tract $(48,49)$ as well as in intestinal epithelial and crypt derived cell lines (50), and may be involved in the response to injury (51-53). Although EGF has not been detected within the intact GI tract (50), Wright and co-workers (54) have identified a novel cell lineage bordering ulcerated areas. The lineage appeared to bud from a stem cell population at the base of intestinal crypts and secreted EGF. The authors speculated that buds were induced by a mesenchymal derived factor in response to injury. KGF would certainly be a leading paracrine candidate mediator of this response.

Thus, rKGF uniquely is a potent inducer of proliferation and differentiation in specific lineages throughout the GI tract. The presence of both receptor and ligand suggests a role for KGF and its receptor in normal maintenance of the gut. Specific diseases where mucosal proliferation and mucin production are limited and states of hepatocyte injury may be future candidates for pharmacological intervention with rKGF. As has been observed in the lung, skin, pancreas, and male genital tract $(8,9$, $12,14,15)$, selective stimulation of cell lineages by rKGF may yield new insights on stem cells, and differentiation processes within the gut and liver as well.

\section{Acknowledgments}

We appreciate the excellent technical assistance of Carol Burgh, Diane Duryea, Cindy Gregory, John Lu, Barry Morris, Rachel Quin, and Larry Ross, graphics by Jennifer Keysor and Rick Pinal, and manuscript preparation by Joan Bennett.

\section{References}

1. Rubin, J. S., H. Osada, P. W. Finch, W. G. Taylor, S. Rudikoff, and S. A. Aaronson. 1989. Purification and characterization of a newly identified growth factor specific for epithelial cells. Proc. Natl. Acad. Sci. USA. 86:802-806.

2. Finch, P. W., J. S. Rubin, T. Miki, D. Ron, and S. A. Aaronson. 1989. Human KGF is FGF-related with properties of a paracrine effector of epithelial cell growth. Science (Wash. DC). 245:752-755.

3. Marchese, C., J. Rubin, D. Ron, A. Faggioni, M. R. Torrisi, A. Messina, L. Frati, and S. A. Aaronson. 1990. Human keratinocyte growth factor activity on proliferation and differentiation of human keratinocytes: differentiation response distinguishes KGF from EGF family. J. Cell. Physiol. 44:326-332.

4. Werner, S., K. V. Peters, M. T. Longaker, F. Fuller-Pace, M. J. Banda, and L. T. Williams. 1992. Large induction of keratinocyte growth factor expression in the dermis during wound healing. Proc. Natl. Acad. Sci. USA. 89:6896-6900.

5. Miki, T., T. Fleming, D. Bottaro, J. Rubin, D. Ron, and S. Aaronson. 1991. Expression cDNA cloning of the KGF receptor by creation of a transforming autocrine loop. Science (Wash. DC). 251:72-75.

6. Miki, T., D. P. Bottaro, T. P. Fleming, C. L. Smith, W. H. Burgess, A. M.-L. Chan, and S. A. Aaronson. 1992. Determination of ligand-binding specificity by alternative splicing: two distinct growth factor receptors encoded by a single gene. Proc. Natl. Acad. Sci. USA. 89:246-250.

7. Hattori, Y., H. Odagiri, H. Nakatani, K. Miyagawa, K. Naito, H. Sakamoto, O. Katoh, T. Yoshida, T. Sugimura, and M. Terada. 1990. K-sam, an amplified gene in stomach cancer, is a member of the heparin-binding growth factor receptor genes. Proc. Natl. Acad. Sci. USA. 87:5983-5987.

8. Ulich, T., E. S. Yi, K. Longmuir, S. Yin, R. Biltz, C. F. Morris, R. M. Housley, and G. F. Pierce. 1994. Keratinocyte growth factor is a growth factor for Type II pneumocytes in vivo. J. Clin. Invest. 93:1298-1306.

9. Pierce, G. F., D. Yanagihara, K. Klopchin, D. M. Danilenko, E. Hsu, W. C. Kenney, and C. F. Morris. 1994. Stimulation of all epithelial elements during skin regeneration by keratinocyte growth factor. J. Exp. Med. 179:831-840.

10. Staiano-Coico, L., J. G. Krueger, J. S. Rubin, S. D'limi, V. P. Vallat, L. Valentino, T. Fahey III, A. Hawes, G. Kingston, M. R. Madden, M. Mathwich, A. B. Gottlieb, and S. A. Aaronson. 1993. Human keratinocyte growth factor effects in a porcine model of epidermal wound healing. J. Exp. Med. 178:865878.

11. Panos, R. S., J. S. Rubin, S. A. Aaronson, and R. J. Mason. 1993. Keratinocyte growth factor and hepatocyte growth factor/scatter factor are heparin binding growth factors for alveolar type II cells in conditioned medium. J. Clin. Invest. 92:969-977.

12. Yi, E. S., S. Yin, D. L. Harclerode, A., Bedoya, N. B. Bikhazi, R. Housley, S. L. Aukerman, C. F. Morris, G. F. Pierce, and T. R. Ulich. 1994. Keratinocyte growth factor induces pancreatic ductal epithelial proliferation. Am. J. Pathol. 145:80-85.

13. Ulich, T. R., E. S. Yi, R. Cardiff, S. Yin, N. Bikhazi, C. F. Morris, and G. F. Pierce. 1994. Keratinocyte growth factor is a growth factor for mammary epithelium in vivo: the mammary epithelium of lactating rats are resistent to the proliferative action of KGF. Am. J. Pathol. 144:862-868.

14. Yan, G., Y. Fukabori, S. Nikolaropoulos, F. Wang, and W. L. McKeehan. 1992. Heparin-binding keratinocyte growth factor is a candidate stromal to epithelial cell andromedin. Mol. Endocrinol. 6:2123-2128. 
15. Alarid, E. T., J. S. Rubin, P. Young, M. Chedid, D. Ron, S. A. Aaronson, and G. R. Cunha. 1994. Keratinocyte growth factor functions in epithelial induction during seminal vesicle development. Proc. Natl. Acad. Sci. USA. 91:10741078.

16. Ron, D., D. P. Bottaro, P. W. Finch, D. Morris, J. S. Rubin, and S. A. Aaronson. 1993. Expression of biologically active recombinant keratinocyte growth factor. Structure/function analysis of amino-terminal truncation mutants. J. Biol. Chem. 268:2984-2988.

17. Chomczynski, P., and N. Sacchi. 1987. Single step method of RNA isolation by acid guanidinium thiocyanate-phenol-chloroform extraction. Anal. Biochem. 162:156.

18. Yan, G., and F. Wang. 1991. Sequence of rat keratinocyte growth factor (heparin-binding growth factor type 7) In Vitro Cell \& Dev. Biol. 27A:437.

19. Sheehan, D. C., and B. B. Hrapchak. 1980. Theory and Practice of Histotechnology, 2nd ed. C. V. Mosby, New York. 481 pp.

20. Whitehead, R. H., H. H. Zhang, and I. P. Hayward. 1992. Retention of tissue-specific phenotype in a panel of colon carcinoma cell lines: relationship to clinical correlates. Immun. Cell Biol. 70:227-236.

21. Devine, P. L., J. A. Warren, B. G. Ward, I. F. C. McKenzie, and G. T. Layton. 1990. Glycosylation and the exposure of tumor-associated epitopes on mucins. J. Tumor Marker Oncol. 5:11-26.

22. Devine, P. L., G. W. Birrell, R. H. Whitehead, H. Harada, P.-X. Xing, and I. F. C. McKenzie. 1992. Expression of MUC1 and MUC2 mucins by human tumor cell lines. Tumor Biol. 13:268-277.

23. Devine, P. L., J. A. Warren, B. A. Clark, G. T. Layton, B. G. Ward, B. MacDonald, P.-X. Xing, and I. F. C. McKenzie. 1990. The complexity of cancerassociated epitope expression on antigens produced by ovarian tumor cells. $J$. Tumor Marker Oncol. 5:321-339.

24. Thorgeirsson, S. S. 1993. Commentary: hepatic stem cells. Am. J. Pathol. 142:1331-1333.

25. Fausto, N. 1991. Growth factors in liver development, regeneration and carcinogenesis. Prog. Growth Factor Res. 3:219-234.

26. McGowan, J. A., A. J. Strain, and N. L. R. Bucher. 1981. DNA synthesis in primary cultures of adult rat hepatocytes in a defined medium: effects of epidermal growth factor, insulin, glucagon, and cyclic-AMP. J. Cell. Physiol. 108:353-363.

27. Nakamura, T., K. Nawa, and A. Ichihara. 1984. Partial purification and characterization of hepatocyte growth factor from serum of hepatectomized rats. Biochem. Biophys. Res. Commun. 122:1450.

28. Houck, K. A., R. Zamegar, S. J. Muga, and G. K. Michalopoulos. 1990. Acidic fibroblast growth factor (HBGF-1) stimulates DNA synthesis in primary rat hepatocyte cultures. J. Cell. Physiol. 143:129-132.

29. Ishiki, Y., H. Ohnishi, Y. Muto, K. Matsumoto, and T. Nakamura. 1992. Direct evidence that hepatocyte growth factor is a hepatotrophic factor for liver regeneration and has a potent antihepatitis effect in vivo. Hepatology. 16:12241235 .

30. Webber, E. M., P. J. Godowski, and N. Fausto. 1994. In vivo response of hepatocytes to growth factors requires an initial priming stimulus. Hepatology. 14:489-497.

31. Itoh, T., M. Suzuki, and Y. Mitsui. 1993. Keratinocyte growth factor as a mitogen for primary culture of rat hepatocytes. Biochem. Biophys. Res. Commun. 192:1011-1015.

32. Strain, A. J., G. McGuinness, J. S. Rubin, and S. A. Aaronson. 1994. Keratinocyte growth factor and fibroblast growth factor action on DNA synthesis in rat and human hepatocytes: modulation by heparin. Exp. Cell. Res. 210:253259.

33. Scheving, L. A., Y. C. Yeh, T. H. Tsai, and L. E. Scheving. 1979. Circadian phase-dependent stimulatory effects of epidermal growth factor on deoxyribonucleic acid synthesis in the tongue, esophagus, and stomach of the adult male mouse. Endocrinology. 105:1475-1480.

34. Johnson, L. R., and P. D. Guthrie. 1980. Stimulation of rat oxyntic gland mucosal growth by epidermal growth factor. Am. J. Physiol. 238:G45-G49.

35. Chen, C. M., A. T. Lee, and A. H. Soll. 1991. Mitogenic response of canine fundic epithelial cells in short-term culture to transforming growth factor $\alpha$ and insulin-like growth factor I. J. Clin. Invest. 87:1716-1723.

36. Takahashi, M., S. Ota, A. Terano, K. Yoshiura, M. Matsumura, Y. Niwa, T. Kawabe, T. Nakamura, and M. Omata. 1993. Hepatocyte growth factor induces mitogenic reaction to the rabbit gastric epithelial cells in primary culture. Biochem. Biophys. Res. Commun. 191:528-534.

37. Potten, C. S., R. Schofield, and L. G. Lajtha. 1979. A comparison of cell replacement in bone marrow, testis and three regions of surface epithelium. Biochim. Biophys. Acta. 560:281-299.

38. Potten, C. S., and J. H. Hendry. 1983. Stem cells in murine small intestine. In Stem Cells. C. S. Potten, editor. Churchill Livingstone. Edinburgh, Scotland. 155-199.

39. Cheng, H., and C. P. Leblond. 1974. Origin, differentiation and renewal of the four main epithelial cell types in the mouse small intestine Am. J. Anat. 141:537-562.

40. Ponder, B. A. J., G. H. Schmidt, M. M. Wilkinson, M. J. Wood, M. Monk, and A. Reid. 1985. Derivation of mouse intestinal crypts from single progenitor cells. Nature (Lond.). 313:689-691.

41. Schmidt, G. H., D. J. Winton, and B. A. J. Ponder. 1988. Development of the pattern of cell renewal in the crypt villus unit of chimeric mouse intestine. Development (Camb.) 103:785-790.

42. Gordon, J. I. 1989. Intestinal epithelial differentiation: new insights from chimeric and transgenic mice. J. Cell Biol. 108:1187-1194.

43. Hermiston, M. L., R. P. Green, and J. I. Gordon. 1993. Chimeric-transgenic mice represent a powerful tool for studying how the intestinal proliferation and differentiation programs of intestinal epithelial cell lineages are regulated. Proc. Natl. Acad. Sci. USA. 99:8866-8870.

44. Sato, M., and D. J. Abnen. 1992. Regional variability of colonocyte growth and differentiation in the rat. Anat. Rec. 233:409-414.

45. Benchimol, S., A. Fuks, S. Jothy, N. Beauchemin, K. Shirota, and C. P. Stanners. 1989. Carcinoembryonic antigen, a human tumor marker, functions as an intercellular adhesion molecule. Cell. 57:327-334.

46. Jothy, S., S. -Y. Yuan, and K. Shirota. 1993. Transcription of carcinoembryonic antigen in normal colon and colon carcinoma. Am. J. Pathol. 143:250257.

47. Toribara, N. W., T. L. Sack, J. R. Gum, S. B. Ho, J. E. Shively, J. K. V. Willson, and Y. S. Kim. 1989. Heterogeneity in the induction and expression of carcinoembryonic antigen-related antigens in human colon cancer cell lines. Cancer Res. 49:3321-3327.

48. Beauchamp, R. D., J. A. Barnard, C. M. McCutchen, J. A. Cherner, and R. J. Coffey, Jr. 1989. Localization of transforming growth factor $\alpha$ and its receptor in gastric mucosal cells. J. Clin. Invest. 84:1017-1023.

49. Barnard, J. A., W. H. Polk, H. L. Moses, and R. J. Coffey. 1991. Production of transforming growth factor- $\alpha$ by normal rat small intestine. Am. J. Physiol. 261:C994-C1000.

50. Koyama, S., and D. K. Podolsky. 1989. Differential expression of transforming growth factors $\alpha$ and $\beta$ in rat intestinal epithelial cells. J. Clin. Invest. 83:1768-1773.

51. Romano, M., W. H. Polk, J. A. Awad, C. L. Arteaga, L. B. Nanney, M. J. Wargovich, E. R. Kraus, C. R. Boland, and R. J. Coffey. 1992. Transforming growth factor $\alpha$ protection against drug-induced injury to the rat gastric mucosa in vivo. J. Clin. Invest. 90:2409-2421.

52. Polk, Jr., W. H., P. J. Dempsey, W. E. Russell, P. I. Brown, R. D. Beauchamp, J. A. Barnard, and R. J. Coffey, Jr. 1992. Increased production of transforming growth factor $\alpha$ following acute gastric injury. Gastroenterology. 102:1467-1474.

53. Tarnawski, A., J. Stachura, T. Durbin, I. J. Sarfeh, and H. Gergely. 1992. Increased expression of epidermal growth factor receptor during gastric ulcer healing in rats. Gastroenterology. 102:695-698.

54. Wright, N. A., C. Pike, and G. Elia. 1990. Induction of a novel epiderma growth factor-secreting cell lineage by mucosal ulceration in human gastrointestinal stem cells. Nature (Lond.). 343:82-85.

55. Loeb, W. F., and F. W. Quimby. 1989. The Clinical Chemistry of Laboratory Animals. Pergamon Press. New York. 519 pp.

56. Kaneko, J. J. 1989. Clinical Biochemistry of Domestic Animals. 4th edition, Academic Press. 932 pp. 